CYSTIC FIBROSIS

\title{
Altered tissue distribution in adults with cystic fibrosis
}

\author{
C E Bolton, A A lonescu, W D Evans, R J Pettit, D J Shale
}

Thorax 2003;58:885-889

See end of article for authors' affiliations

(n)

Correspondence to: Professor D J Shale, Section of Respiratory Medicine, University of Wales College of Medicine, University Hospital of Wales, Cardiff, CFI 4 4XN, UK shaledj@cardiff.ac.uk

Revised version received 6 June 2003

Accepted for publication

29 June 2003
Background: Regional body composition was determined in adults with cystic fibrosis (CF). Our hypothesis was that dual energy $x$ ray absorptiometry (DXA) scanning could assess the fat free mass, bone mineral content, and fat mass and determine the distribution of the changes.

Method: Height squared indices were derived for fat mass (FMI), fat free mass (FFMI), and bone mineral content (BMCl) of the arm, leg, and trunk by DXA in 51 patients and 18 age/sex matched healthy subjects. Results: The arm and leg FFMI in patients were less than in healthy controls $(p<0.05)$; the deficit was leg $>$ arm $>$ trunk $(-18.19 \%,-14.86 \%,+0.09 \%, p<0.02)$ and was related to severity of lung disease. Patients with a normal BMI and low total FFM (hidden loss) had a lower arm, leg and trunk FFMI than those with a normal $\mathrm{BMI}$ and total FFM $(\mathrm{p}<0.05)$. The $\mathrm{BMCl}$ for all body segments was lower in patients than in controls $(p<0.001)$. The BMCl was lower in the leg and trunk $(p<0.01)$ in patients with severe disease than in those with mild lung disease. In those with hidden FFM loss the BMCl was lower $(p<0.05$ in leg and trunk). There was no difference in the $\mathrm{BMCl}$ deficit between body segments. Fat mass in patients was not reduced.

Conclusion: Preferential loss of FFM is related to severity of lung disease and occurs in patients with a normal BMI. A similar loss of BMC occurs while FM is preserved. A hierarchical pattern of FFM loss of legs $>$ arms > trunk was shown; BMC loss was evenly distributed.
I: n cystic fibrosis (CF) both weight loss and altered body composition are associated with greater morbidity and mortality. ${ }^{1}$ Such changes may be related to an imbalance between energy intake and energy needs. ${ }^{2}$ The causes of this imbalance probably include the severity of the lung disease, impaired inspiratory muscle function, and systemic inflammation. ${ }^{3}{ }^{4}$ Physical inactivity, reduced sex hormone levels, increased resting energy expenditure, and hypoinsulinaemia may also be contributing factors.

In routine clinical practice body mass index (BMI) is widely used to assess nutritional status, but does not inform on body composition and may fail to detect subtle alterations in body composition. An inapparent loss of skeletal muscle may occur in patients who retain their normal body weight. ${ }^{5-7}$ Various methods are available for the determination of body composition. ${ }^{8-10}$ Dual energy $x$ ray absorptiometry (DXA) has the advantage of giving whole body composition in terms of fat mass (FM), fat free mass (FFM), and bone mineral content (BMC) - the actual mineral, calcium hydroxyapatite. Subregional analysis of the tissues in the limbs and trunk has been performed in healthy subjects ${ }^{11}$ and in a few disease states including chronic obstructive pulmonary disease. DXA has been used to compare peripheral and central distribution of body composition, ${ }^{12}{ }^{13}$ to quantify the effects of growth hormone treatment on FFM, ${ }^{14}$ and to relate muscle mass to strength of the lower limb ${ }^{15}{ }^{16}$ and physical disability. ${ }^{17}$

Based on the altered body composition, particularly loss of FFM, seen in patients with CF and its association with the severity of lung disease, systemic inflammation, resting energy expenditure, catabolic intermediary metabolism and the rate of exacerbations of respiratory symptoms, ${ }^{3418}$ we hypothesised that DXA scanning could be used to determine regional body composition in adult patients with $\mathrm{CF}$. We further hypothesised that differences would occur in regional body composition because underlying multiple causative factors were likely to have differential effects. We also expected evidence of preferential loss of FFM and BMC in some patients due to the previously reported protein catabolic state.

\section{METHODS \\ Patients}

Fifty one adults ( 25 men) with proven CF (sweat $\mathrm{Na}^{+}$and $\mathrm{Cl}^{-}$ $>70 \mathrm{mmol} / \mathrm{l}$ and a CF genotype) and chronically infected with Pseudomonas aeruginosa were studied when clinically stable-defined as no change in pulmonary symptoms, no new systemic symptoms, no change in medication, and a $<10 \%$ reduction in forced expiratory volume in one second $\left(\mathrm{FEV}_{1}\right)$ in the month before the assessment. Eighteen healthy subjects (nine men) were also studied. The study was approved by the local research ethics committee and all subjects gave full written consent.

\section{Body composition}

Weight was determined with an electronic scale and height was measured bare foot with a stadiometer. Body mass index (BMI) was calculated $\left(\mathrm{kg} / \mathrm{m}^{2}\right)$.

\section{Dual energy $x$ ray absorptiometry (DXA)}

Whole body DXA scans (Hologic QDR2000+, Hologic Inc, Waltham, MA, USA) were performed before a meal and with an empty bladder. Subjects were scanned supine using a pencil beam mode, enhanced software, and a calculated radiation dose of $4.6 \mu \mathrm{Sv}$. Each scan took 15-20 minutes. The coefficient of variation (CV) of the Hologic QDR 2000+ for whole body calculation was $0.4-1.0 \% .^{19}$ The BMC, FM and FFM (excluding BMC) were determined and corrected for body habitus using height squared to give indices BMCI, FMI, and FFMI which were calculated for each limb and the trunk. A height squared ratio was used to control for the influence of potential delayed or impaired growth, which is particularly important in $\mathrm{CF}$, and to allow comparisons between mixed sex groups. ${ }^{20-22}$ Limb segments were identified using the DXA software with operator adjustment to 
ensure that the upper limb was demarcated by a line between the head of the humerus and glenoid fossa and the lower limb demarcated by a line made through the femoral neck. The head was separated from the trunk at the inferior level of the mandible. Comparison was made between the right and left limbs and no difference was found within patients or healthy subjects between the two upper limbs and the two lower limbs for each tissue component. The right arm and right leg were therefore selected in each subject for direct comparison.

In the healthy subjects FFM was within the limits of a healthy UK population of the same age and sex, although these data were generated from anthropometric measurements. ${ }^{23}$ Patients were defined by their total FFM by DXA: (1) low FFM was less than the lower 5 th percentile for healthy subjects $^{22}$; (2) normal FFM was more than the lower 5th percentile for healthy subjects. ${ }^{20}$

\section{Lung function}

Forced expiratory volume in 1 second $\left(\mathrm{FEV}_{1}\right)$, forced vital capacity (FVC), and their ratio were determined in the patients as the best of three measurements by spirometric testing (Vitalograph Ltd, Bucks, UK). For analysis based on the severity of lung disease, patients were defined by airways obstruction: mild impairment $=\mathrm{FEV}_{1} \geqslant 65 \%$ predicted; moderate impairment $=\mathrm{FEV}_{1} \quad>46-<65 \%$ predicted; severe impairment $=\mathrm{FEV}_{1} \leqslant 45 \%$ predicted $^{24}$

\section{Physical activity}

This was determined in patients using a recall questionnaire relating to physical activity in the preceding month. The activity score was expressed in METS ( 1 MET = the energy expended by a person at rest). ${ }^{25}$

\section{Analysis of data}

Data were normally distributed and are presented as mean (SD) values. Differences between populations are presented as mean (95\% confidence interval, 95\% CI). Continuous variables with normal distributions were compared using either $t$ tests or one way ANOVA when three groups were compared. All statistical analyses were performed using the Statistical Package for Social Sciences (SPSS) for Windows, Version 11.0. A p value of $<0.05$ was considered statistically significant. Pearson's correlation coefficients were calculated and multivariate linear regression analysis determined the significance of these independent factors.

To define tissue deficits we used the mean for the healthy subjects (presumed "ideal") for a given tissue (FFMI, FMI and BMCI) in a given compartment (arm, leg and trunk) and

Table 1 Demographic characteristics of study subjects

\begin{tabular}{lll}
\hline & Patients $(\mathbf{n}=51)$ & Healthy subjects $(\mathbf{n}=\mathbf{1 8})$ \\
\hline Age (years) & $23.3(5.5)$ & $23.3(3.5)$ \\
$\mathrm{FEV}_{1}(\%$ predicted) & $56.4(23.9)$ & - \\
$\mathrm{BMI}\left(\mathrm{kg} / \mathrm{m}^{2}\right)$ & $20.67(2.86)^{*}$ & $22.58(1.75)$ \\
Total FFM $(\mathrm{kg})$ & $40.62(8.77)^{*}$ & $47.4(9.36)$ \\
Total FFMI $\left(\mathrm{kg} / \mathrm{m}^{2}\right)$ & $15.02(2.28)$ & $16.13(1.84)$ \\
Height $(\mathrm{cm})$ & $163.7(9.03)^{*}$ & $170.6(9.8)$ \\
Men & $169.8(2.83)^{*} \dagger$ & $177.6(6.19) \dagger$ \\
Women & $157.8(6.43)^{*}$ & $163.7(7.57)$ \\
METS & $35.81(7.8)^{*}$ & $44.3(6.15)$ \\
\hline
\end{tabular}

$\mathrm{FEV}_{1}=$ forced expiratory volume in 1 second; $\mathrm{BMI}=$ body mass index; FFM = fat free mass; FFMI = fat free mass index; $M E T S=$ activity score. *Significant difference between patients and healthy subjects. †Significant difference between sexes in the same population. Data are presented as mean (SD). expressed each patient's result for the same tissue and compartment as a proportion.

\section{RESULTS}

The demographic characteristics of the subjects are shown in table 1 . Of the 51 patients, 28 (12 men) had a low BMI $\left(<19.9 \mathrm{~kg} / \mathrm{m}^{2}\right)$ of which 21 (6 men) also had a low FFMI. Of the 23 patients with a normal BMI, 10 ( 3 men) had a low FFMI (hidden FFM loss) while the other 13 ( 10 men) had a normal FFMI. Men were significantly taller in both populations together, with the patients being shorter than the healthy subjects.

\section{Comparison of body composition between whole patient group and healthy subjects}

Fat free mass index (FFMI)

The arm and leg FFMI were lower in patients than in healthy subjects while the trunk FFMI was similar (table 2). The absolute difference in arm, leg and trunk FFMI $\left(\mathrm{kg} / \mathrm{m}^{2}\right)$ compared with healthy subjects followed the same pattern for the group as a whole and for each sex separately. The mean difference $(95 \% \mathrm{CI})$ for the men was: arm -0.126 $(-0.216$ to -0.036$), p=0.008$; leg $-0.412 \quad(-0.677$ to $-0.147), \quad p=0.003$; trunk $0.231 \quad(-0.375$ to 0.836$)$, $\mathrm{p}=0.443$, and for the women was: arm $-0.108(-0.191$ to $-0.026), \mathrm{p}=0.01 \mathrm{l}$; leg $-0.506(-0.719$ to -0.292$), \mathrm{p}<0.001$; trunk $-0.19(-0.824$ to 0.444$), \mathrm{p}=0.547$.

The proportionate FFMI deficit in patients was greatest in the leg, followed by the arm and then the trunk. The difference in deficit between body segments was significant $(p<0.02)$ in all cases (fig 1$)$. The arm, leg, and trunk FFMI were individually related to physical activity $(r=0.555$, $\mathrm{p}<0.001 ; r=0.652$, $\mathrm{p}<0.001 ;$ and $r=0.507, \mathrm{p}<0.001$, respectively); using multivariate regression, this independent factor was significant (arm $7.4 \%$, leg $17.1 \%$, trunk $10.2 \%$ ).

Bone mineral content index (BMCI)

The BMCI was less in patients than in healthy subjects for the arm, leg and trunk (table 2). The BMCI in each body region of the patients compared with the mean BMCI of the healthy subjects was reduced, but was not different between each region (fig 2).

\section{Fat mass index (FMI)}

There was no difference in FMI between patients and healthy subjects for any body segment (table 2). There was an inverse relationship between arm FMI and FFMI $(r=-0.4$, $\mathrm{p}=0.003)$ and leg FMI and FFMI $(r=-0.339, \mathrm{p}=0.015)$, indicating preferential loss of FFM.

\section{Severity of lung disease and changes in body composition \\ Fat free mass index}

There were 20 patients with mild disease, 11 with moderate lung disease, and 20 whose disease was categorised as severe. A comparison was made between the mild and severe subgroups to determine the extremes of the spectrum. The FFMI for all body segments was less in the severe lung disease group than in the mild group (all $\mathrm{p}<0.05$, table 3 ). The deficit in FFMI in the severe group followed the pattern of leg $(-28.68 \%)>\operatorname{arm}(-23.76 \%)>\operatorname{trunk}(-3.93 \%)$, and the differences between the three regions were significant (all $\mathrm{p}<0.02$, fig 1). The leg, arm and trunk FFMI in the patients with severe lung disease were each related to the $\mathrm{FEV}_{1}(r=0.556, \mathrm{p}<0.001 ; r=0.429, \mathrm{p}=0.002 ; r=0.418$, $\mathrm{p}=0.003$, respectively). Multiple regression indicated that $\mathrm{FEV}_{1}$ was a significant independent factor for the leg (4.2\%).

There was no difference in FFMI in any segment between patients with mild disease and healthy subjects. 
Table 2 Comparison of indexed tissue parameters $\left(\mathrm{kg} / \mathrm{m}^{2}\right)$ in each of the body segments between patients and healthy subjects

\begin{tabular}{|c|c|c|c|}
\hline & Arm & Leg & Trunk \\
\hline \multicolumn{4}{|l|}{ FFMI $\left(\mathrm{kg} / \mathrm{m}^{2}\right):$} \\
\hline Healthy subjects: mean (SE) & $0.81(0.04)$ & $2.56(0.1)$ & $8.31(0.18)$ \\
\hline Mean difference $(95 \% \mathrm{CI})$ & $-0.12^{*}(-0.22$ to -0.02$)$ & $-0.47^{*}(-0.72$ to -0.21$)$ & $0.01(-0.53$ to 0.54$)$ \\
\hline \multirow{2}{*}{\multicolumn{4}{|c|}{$\operatorname{BMCl}\left(\mathrm{kg} / \mathrm{m}^{2}\right):$}} \\
\hline & & & \\
\hline Healthy subjects: mean (SE) & $0.057(0.002)$ & $0.186(0.05)$ & $0.254(0.006)$ \\
\hline Mean difference $(95 \% \mathrm{CI})$ & $-0.011^{*}(-0.016$ to -0.006$)$ & $-0.040^{*}(-0.054$ to -0.026$)$ & $-0.052^{*}(-0.07$ to -0.03$)$ \\
\hline $\begin{array}{l}\text { Patients: mean (SE) } \\
\text { FMI }\left(\mathrm{kg} / \mathrm{m}^{2}\right) \text { : }\end{array}$ & $0.046(0.001)$ & $0.145(0.004)$ & $0.202(0.005)$ \\
\hline Healthy subjects: mean (SE) & $0.31(0.03)$ & $1.23(0.11)$ & $1.94(0.17)$ \\
\hline Mean difference $(95 \% \mathrm{Cl})$ & $-0.02(-0.11$ to 0.06$)$ & $-0.23(-0.48$ to 0.03$)$ & $-0.03(-0.63$ to 0.56$)$ \\
\hline Patients: mean (SE) & $0.29(0.02)$ & $1.0(0.06)$ & $1.91(0.17)$ \\
\hline
\end{tabular}

${ }^{*} p<0.05$. Difference between means is documented and a negative difference indicates a loss of the indexed parameter in the patient. $\mathrm{FFMI}=$ fat free mass index; $\mathrm{BMCl}=$ bone mineral content index; $\mathrm{FMI}=$ fat mass index .

Bone mineral content index

The BMCI was reduced for the leg and trunk in the group with severe lung disease compared with the mild group (table 3). The deficit in the arm, leg, and trunk in the group with severe disease did not differ between the three body compartments ( $p>0.05$, fig 2 ).

The BMCI was lower in all three segments in patients with mild disease than in the healthy controls $(p<0.01$ in all cases).

\section{Comparison between patients with normal BMI and total FFM and those with hidden FFM loss}

Fat free mass index

Patients with hidden FFM loss had a lower $(\mathrm{p}<0.05)$ mean (95\% CI) FFMI for the arm, leg, and trunk (difference -0.24 $(-0.38$ to -0.10$),-0.66(-0.98$ to -0.33$)$ and $-1.01(-1.73$ to -0.29$) \mathrm{kg} / \mathrm{m}^{2}$ respectively) compared with those with a normal BMI and total FFM. The distribution of the FFMI deficit in the hidden loss group (related to the healthy subject "ideal") was similar in the arm $(-25.02 \%)$ and leg $(-24.48 \%, p=0.889)$, while both these deficits were greater than the trunk deficit $(-1.77 \%, \mathrm{p}<0.001$; fig 3$)$. No deficit in the arm, leg, or trunk was detected in patients with a normal BMI and total FFM compared with the healthy subjects (fig 3).

Bone mineral content index

A lesser BMCI also occurred in the hidden loss group compared with the group with normal BMI and total FFM.

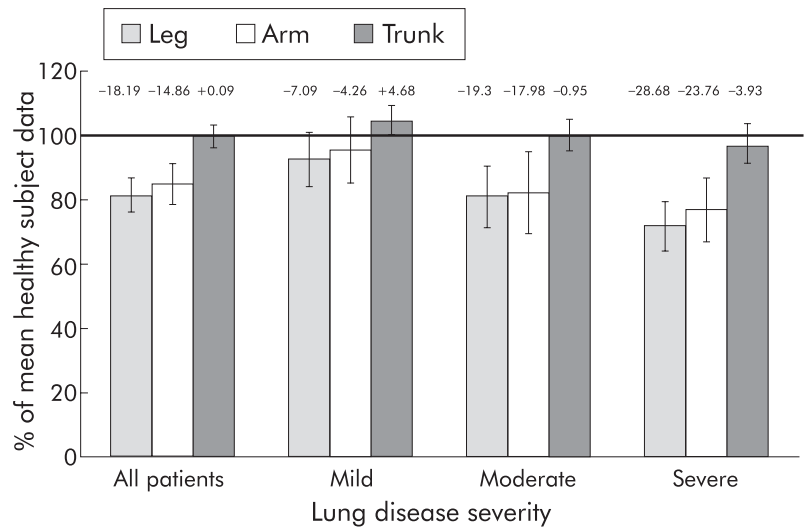

Figure 1 Fat free mass index (FFMI) in the whole patient population and stratified according to the severity of airways obstruction. The difference between the mean patient data and the $100 \%$ "ideal" is the deficit (\%) and is presented numerically above the graph.
The mean $(95 \% \mathrm{CI})$ differences $\left(\mathrm{kg} / \mathrm{m}^{2}\right)$ between these two groups were: $\operatorname{arm}-0.007$ ( -0.016 to 0.001$), p=0.09$; leg $-0.021(-0.042$ to -0.0002$), p=0.047$; and trunk -0.032 $(-0.06$ to -0.006$), p=0.012$. There was no significant difference $(p>0.05)$ between the arm, leg, or trunk for the deficit of BMCI (fig 4) in the group with hidden loss.

\section{Comparison between patients with a hidden FFM loss and those with a low BMI and total FFM \\ Fat free mass index}

There was no statistical difference in the FFMI in any body region between patients with hidden loss and those with a low BMI and total FFM $(\mathrm{p}>0.05)$.

\section{Bone mineral content index}

The BMCI in the low BMI, low total FFM group was less than in the hidden FFM loss group. The mean differences $\left(\mathrm{kg} / \mathrm{m}^{2}\right)$ were: $\operatorname{arm}-0.01(-0.02$ to -0.003$), p=0.004$; leg -0.026 $(-0.046$ to -0.008$), p=0.003$; and trunk $-0.024(-0.049$ to $0.001), p=0.057$. There was no significant difference in the deficit of BMCI (fig 4) between body regions $(p>0.05)$ in the patients with a low BMI and a low total FFM.

\section{DISCUSSION}

Use of DXA scanning allowed quantification of key components of body composition in the limbs and the trunk of patients with CF and chronic pulmonary infection with $P$ aeruginosa. The pattern of change indicated that such patients

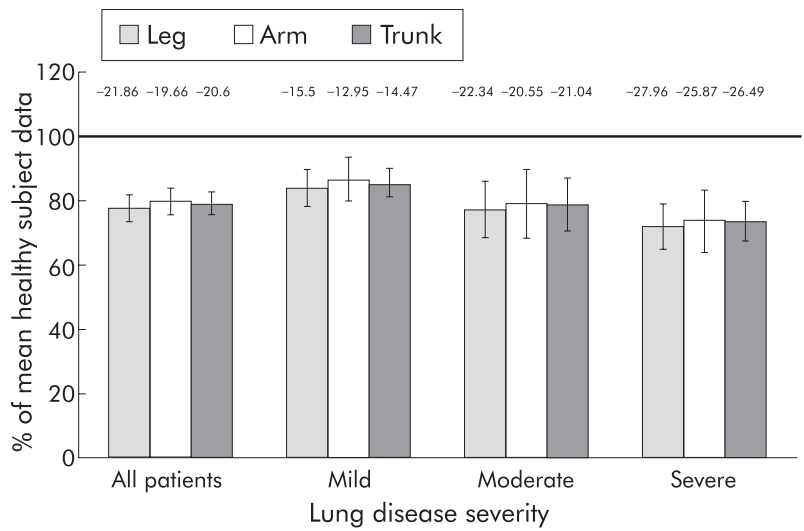

Figure 2 Bone mineral content index (BMCI) in the whole patient population and stratified according to the severity of airways obstruction. The difference between the mean patient data and the 100\% "ideal" is the deficit (\%) and is presented numerically above the graph. 
Table 3 Comparison of indexed tissue parameters between patients with mild and severe lung disease for each body segment

\begin{tabular}{|c|c|c|c|}
\hline & Arm & Leg & Trunk \\
\hline \multicolumn{4}{|l|}{ FFMI $\left(\mathrm{kg} / \mathrm{m}^{2}\right):$} \\
\hline Mild lung disease: mean (SE) & $0.78(0.04)$ & $2.38(0.104)$ & $8.70(0.19)$ \\
\hline Mean difference $(95 \% \mathrm{Cl})$ & $-0.16^{*}(-0.29$ to -0.03$)$ & $-0.55^{*}(-0.88$ to -0.22$)$ & $-0.72(-1.49$ to 0.06$)$ \\
\hline Severe lung disease: mean (SE) & $0.62(0.04)$ & $1.83(0.09)$ & $7.98(0.28)$ \\
\hline \multicolumn{4}{|l|}{$\operatorname{BMCl}\left(\mathrm{kg} / \mathrm{m}^{2}\right):$} \\
\hline Mild lung disease: mean (SE) & $0.05(0.001)$ & $0.157(0.005)$ & $0.217(0.06)$ \\
\hline Mean difference $(95 \% \mathrm{Cl})$ & $-0.007(-0.015$ to 0.00$)$ & $-0.023^{*}(-0.043$ to -0.004$)$ & $-0.031^{*}(-0.054$ to -0.007$)$ \\
\hline Severe lung disease: mean (SE) & $0.042(0.002)$ & $0.134(0.006)$ & $0.187(0.007)$ \\
\hline
\end{tabular}

had a preferential loss of FFM and BMC compared with FM. In addition, there was a differential distribution of FFM loss between the limbs and trunk, suggesting loss of skeletal muscle, a major component of limb FFM. Loss of truncal skeletal muscle may have been partly obscured by the inclusion of viscera in the measurement of FFM and represents a limitation of DXA scanning which cannot distinguish body wall musculature from the viscera. Other protein rich tissue such as bone organic matrix may also be lost, although a differential pattern of loss of BMC was not found. ${ }^{34}$

It is likely that many mechanisms underlie the loss of FFM in our patients including reduced physical activity and catabolic intermediary metabolism causing increased cellular and connective tissue proteolysis. ${ }^{3}$ Continuous catabolic intermediary metabolism could explain the preferential loss of FFM, largely affecting muscle mass, and bone organic matrix proteins with reduced bone mineralisation. Such a systemic process might be expected to cause a diffuse pattern of loss as found with the BMC. The $15 \%$ reduction in upper limb FFMI seems excessive for the effect of reduced activity alone and, perhaps, indicates that a major component of FFM loss here is due to a systemic mechanism. However, the hierarchical leg, arm and trunk pattern of differential FFM loss may reflect an additional effect of other mechanisms such as reduced physical activity, which might have its major impact on leg muscles. The relationship between loss of FFM and physical inactivity tends to support this interpretation, but a cross sectional study does not allow causative mechanisms to be determined. A longitudinal study may indicate whether loss of FFM and hence skeletal muscle leads to reduced activity or whether the FFM loss is largely due to disuse.

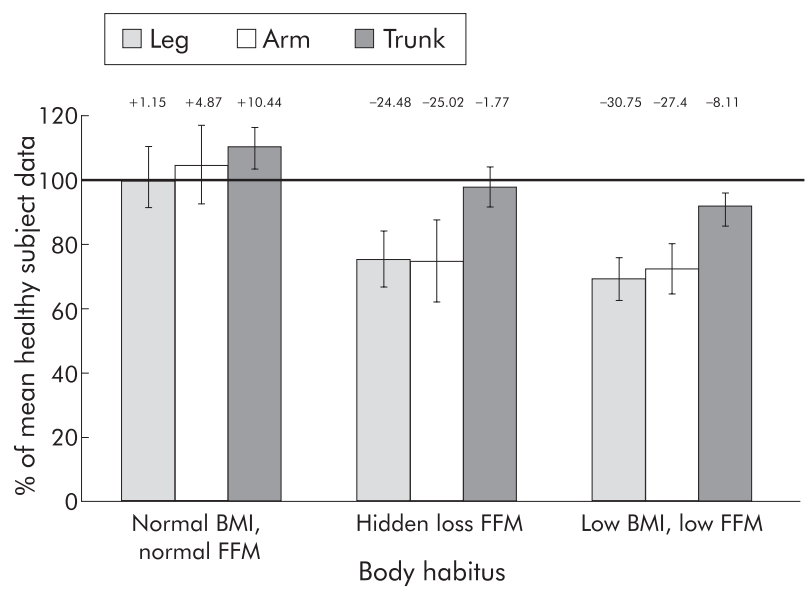

Figure $3 \mathrm{FFMI}$ in the whole patient population and stratified according to their total body habitus. The difference between the mean patient data and the $100 \%$ "ideal" is the deficit (\%) and is presented numerically above the graph.
The hierarchical pattern of FFM loss between the limbs and the trunk was also evident when composition was related to the severity of lung disease, which may have had its effects through inflammatory catabolic mechanisms and physical inactivity. In this group of patients as a whole we have previously reported increased excretion of N-telopeptides of collagen-1 (NTx) which was related to the severity of lung disease and systemic inflammation. ${ }^{3}$ This also supports the view that reduced physical activity may have a lesser effect than the systemic inflammatory catabolic response, although this interpretation is speculative. The possibility that a systemic process had a major effect on FFM loss is supported by the lack of difference between arm and leg FFM deficit in the hidden FFM loss group and by the nonsegmental separation of the loss of BMC in all analyses.

The maintenance of FM suggests preferential systemic proteolysis which predominantly causes skeletal muscle and bone organic matrix loss. This could be explained by enhanced utilisation of protein for energy production in response to a negative energy balance and the pro-proteolytic effects of the catabolic intermediary metabolism that occurs in such patients. The preservation of FM explains the limited value of BMI as an indicator of body composition changes and how hidden loss of FFM can occur. However, these patients show evidence of lipolysis, which may represent futile lipid cycling. ${ }^{26}{ }^{27}$ These changes also indicate that the energy imbalance in CF is not simply a malnutrition like response to starvation, but more resembles an acute response to trauma or infection. ${ }^{28}$

\section{Limitations of the study}

We used DXA with available software in preference to other methods to determine regional body composition. This study

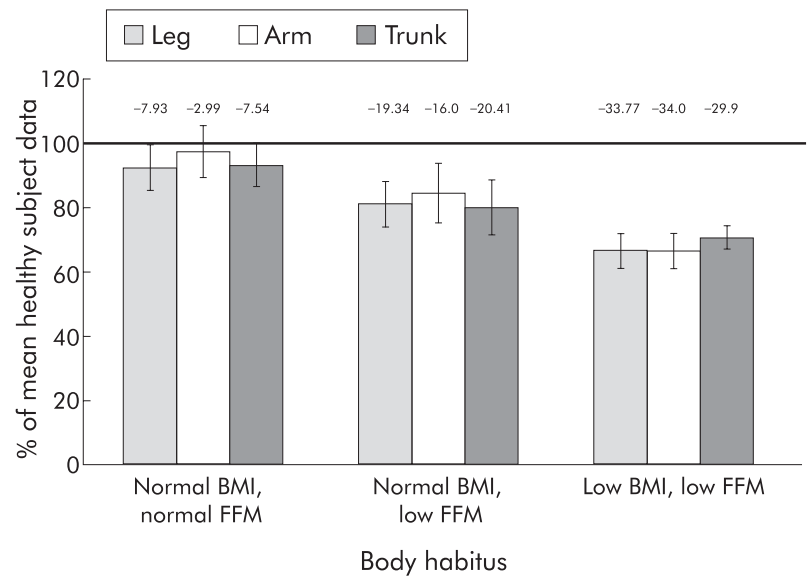

Figure $4 \mathrm{BMCl}$ in the whole patient population and stratified according to their total body habitus. The difference between the mean patient data and the $100 \%$ "ideal" is the deficit (\%) and is presented numerically above the graph. 
could be criticised for using DXA data without applying corrections for acknowledged assumptions. ${ }^{11}$ In other studies body composition has been determined in subregions with extensive use of corrections for tissue hidden by bone and to allow for limb shape before comparing differences between subjects. However, most of these studies were in small groups of healthy subjects of different body habitus. We did not use such corrections because they make a number of methodological assumptions and it is unclear if they are applicable to patients. ${ }^{11}$ In addition, the accuracy and repeatability of DXA are high and difficult to supersede without significant radiation exposure or resource implications. ${ }^{1129} 30$ There is no consensus as to how the results of regional body composition should be expressed and various ratios have been published. From a clinical perspective, DXA allows determination of total body content of three major tissue groups and, as shown here, can detect differences in tissue composition of the limbs and trunk. This is achieved with a low radiation exposure in a quick and convenient manner. Its availability is becoming more widespread and has the added benefit of determining the bone mineral density. This has added clinical value in patients with respiratory disease who may be more susceptible to osteoporosis.

Using DXA scanning, we were able to show preferential FFM loss in patients with CF and chronic $P$ aeruginosa infection and a differential pattern of changes in segmental tissue composition suggestive of the effects of various mechanisms underlying FFM loss. These findings suggest that DXA scanning may have a useful role in the assessment of patients with chronic respiratory diseases associated with loss of body mass.

\section{ACKNOWLEDGEMENTS}

This study was supported by the Cystic Fibrosis Trust (UK), the Astra Foundation (UK), the British Lung Foundation, and the British Thoracic Society.

\section{Authors' affiliations}

C E Bolton, A A lonescu, D J Shale, Section of Respiratory and Communicable Diseases, Department of Medicine, University of Wales College of Medicine, Llandough Hospital, Cardiff and Vale NHS Trust, Penarth, South Glamorgan CF64 2XX, UK

W D Evans, R J Pettit, Department of Imaging and Bio-engineering, University of Wales College of Medicine, University Hospital of Wales, Cardiff CF14 4XN, UK

Conflict of interest: none.

\section{REFERENCES}

1 Shale DJ. Predicting survival in cystic fibrosis. Thorax 1997;52:309.

2 Bell SC, Saunders MJ, Elborn JS, et al. Resting energy expenditure and oxygen cost of breathing in patients with cystic fibrosis. Thorax 1996;51:126-31.

3 lonescu AA, Nixon LS, Luzio S, et al. Pulmonary function, body composition, and protein catabolism in adults with cystic fibrosis. Am J Respir Crit Care Med 2002; 165:495-500.

4 lonescu AA, Nixon LS, Evans WD, et al. Bone density, body composition, and inflammatory status in cystic fibrosis. Am J Respir Crit Care Med 2000; 162:789-94.

5 Eid AA, lonescu AA, Nixon LS, et al. Inflammatory response and body composition in chronic obstructive pulmonary disease. Am J Respir Crit Care Med 2001;164:1414-8.
6 Marquis K, Debigare R, Lacasse Y, et al. Midthigh muscle cross-sectional area is a better predictor of mortality than body mass index in patients with chronic obstructive pulmonary disease. Am J Respir Crit Care Med 2002;166:809-13.

7 Schols AM, Soeters PB, Dingemans AM, et al. Prevalence and characteristics of nutritional depletion in patients with stable COPD eligible for pulmonary rehabilitation. Am Rev Respir Dis 1993;147:1151-6.

8 Pritchard JE, Nowson CA, Strauss BJ, et al. Evaluation of dual energy X-ray absorptiometry as a method of measurement of body fat. Eur J Clin Nutr 1993;47:216-28

9 Steiner MC, Barton RL, Singh SJ, et al. Bedside methods versus dual energy Xray absorptiometry for body composition measurement in COPD. Eur Respir J 2002; 19:626-31.

10 Slosman DO, Casez JP, Pichard C, et al. Assessment of whole-body composition with dual-energy $x$-ray absorptiometry. Radiology 1992; 185:593-8.

11 Fuller NJ, Laskey MA, Elia M. Assessment of the composition of major body regions by dual-energy $X$-ray absorptiometry (DEXA), with special reference to limb muscle mass. Clin Physiol 1992; 12:253-66.

12 Chauveau $P$, Barthe N, Rigalleau V, et al. Outcome of nutritional status and body composition of uremic patients on a very low protein diet. Am J Kidney Dis 1999;34:500-7.

13 Engelen MP, Schols AM, Does JD, et al. Skeletal muscle weakness is associated with wasting of extremity fat-free mass but not with airflow obstruction in patients with chronic obstructive pulmonary disease. Am J Clin Nutr 2000;71:733-8.

14 Taaffe DR, Lewis B, Marcus R. Regional fat distribution by dual-energy X-ray absorptiometry: comparison with anthropometry and application in a clinical trial of growth hormone and exercise. Clin Sci (Lond) 1994;87:581-6.

15 Elkin SL, Williams L, Moore M, et al. Relationship of skeletal muscle mass, muscle strength and bone mineral density in adults with cystic fibrosis. Clin Sci (Lond) 2000;99:309-14.

16 Visser M, Deeg DJ, Lips $P$, et al. Skeletal muscle mass and muscle strength in relation to lower-extremity performance in older men and women. J Am Geriatr Soc 2000;48:381-6.

17 Visser M, Harris TB, Langlois J, et al. Body fat and skeletal muscle mass in relation to physical disability in very old men and women of the Framingham Heart Study. J Gerontol A Biol Sci Med Sci 1998;53:M214-21.

18 lonescu AA, Chatham K, Davies CA, et al. Inspiratory muscle function and body composition in cystic fibrosis. Am J Respir Crit Care Med 1998;158:1271-6.

19 Wahner HW, Fogelman I. The evaluation of osteoporosis: dual energy x-ray absorptiometry in clinical practice, London: Martin Dunitz, 1993.

20 Vanltallie TB, Yang MU, Heymsfield SB, et al. Height-normalized indices of the body's fat-free mass and fat mass: potentially useful indicators of nutritional status. Am J Clin Nutr 1990;52:953-9.

21 Schols AM, Buurman WA, Staal van den Brekel AJ, et al. Evidence for a relation between metabolic derangements and increased levels of inflammatory mediators in a subgroup of patients with chronic obstructive pulmonary disease. Thorax 1996;51:819-24.

22 Shoup R, Dalsky G, Warner S, et al. Body composition and health-related quality of life in patients with obstructive airways disease. Eur Respir J 1997; 10:1576-80.

23 Office of Population Census and Surveys. The dietary and nutritional survey of British adults, London: HMSO, 1990:237.

24 Konstan MW, Byard PJ, Hoppel CL, et al. Effect of high-dose ibuprofen in patients with cystic fibrosis. N Engl J Med 1995;332:848-54.

25 Wilson PW, Paffenbarger RSJ, Morris JN, et al. Assessment methods for physical activity and physical fitness in population studies: report of a NHLBI workshop. Am Heart J 1986;111:1177-92.

26 Grunfeld C, Adi S, Soued M, et al. Search for mediators of the lipogenic effects of tumor necrosis factor: potential role for interleukin 6. Cancer Res 1990;50:4233-8.

27 Feingold KR, Soued M, Adi S, et al. Tumor necrosis factor-increased hepatic very-low-density lipoprotein production and increased serum triglyceride levels in diabetic rats. Diabetes 1990;39:1569-74.

28 Miller M, Ward L, Thomas BJ, et al. Altered body composition and muscle protein degradation in nutritionally growth-retarded children with cystic fibrosis. Am J Clin Nutr 1982;36:492-9.

29 Mazess RB, Barden HS, Bisek JP, et al. Dual-energy x-ray absorptiometry for total-body and regional bone-mineral and soft-tissue composition. Am J Clin Nutr 1990;51:1106-12.

30 Going SB, Massett MP, Hall MC, et al. Detection of small changes in body composition by dual-energy x-ray absorptiometry. Am J Clin Nutr 1993:57:845-50. 